\title{
OTIMIZAÇÃO DOS PARÂMETROS DE SECAGEM PARA MINIMIZAÇÃO DO CUSTO ENERGÉTICO NUM SECADOR CONVECTIVO DE ALIMENTOS
}

\author{
CAMILA N. BOERI ${ }^{1,2}$, FERNANDO J. NETO DA SILVA ${ }^{1}$, JORGE A. F. FERREIRA ${ }^{1}$.
}

\author{
1. Centro de Tecnologia Mecânica e Automação, Departamento de Engenharia Mecânica, \\ Universidade de Aveiro - Aveiro - Portugal \\ E-mails: camilaboeri@ua.pt, fneto@ua.pt, jaff@ua.pt
}
2. Departamento de Ciências Exatas e da Terra, Universidade Regional Integrada do Alto Uruguai e das Missões - Campus Frederico Westphalen
Rua Assis Brasil, 709 - Caixa Postal: 184 - CEP 98400-000 - Frederico Westphalen - RS

\begin{abstract}
The economic viability of a drying system is extremely important because the product final cost on the market depends directly on all expenditures necessary for its processing. Thus, the drying has a great importance from the standpoint of maintenance and cost of the final product. With regard to the drying of fish, there are few works dealing costs, despite the high energy consumption and the importance of drying is after the catch. This work aims to present the codfish drying costs, showing the energy consumption of the convective experimental installation for different operating conditions and perform the optimization of these conditions to reduce energy consumption.
\end{abstract}

Keywords_ - Optimization, drying costs, energy consumption.

Resumo- A viabilidade econômica de um sistema de secagem é de extrema relevância, pois o custo final do produto colocado no mercado depende diretamente de todos os gastos necessários para o seu processamento. Assim, a secagem é uma das etapas de grande importância do ponto de vista da conservação e do custo final do produto. No que diz respeito à secagem de peixes, existem poucos trabalhos que tratam dos custos, apesar do elevado consumo de energia e da importância que a secagem representa após a captura. Assim, este trabalho tem por objetivo apresentar os custos da secagem do bacalhau, mostrando o consumo energético da instalação experimental convectiva para diferentes condições operacionais, bem como realizar a otimização destas condições para reduzir o consumo energético.

Palavras-chave— Otimização, custos de secagem, consumo energético

\section{Introdução}

A secagem e a armazenagem de produtos agroalimentares constituem uma importante e dispendiosa etapa da cadeia produtiva de alimentos, e fortemente ligada à qualidade final do produto. Conforme Youcef et al. (2001), os custos relativos a esta etapa requerem atenção especial dos gestores, pois se forem elevados podem comprometer uma significativa parcela de rentabilidade ao fim do processo de produção e comercialização. De acordo com Martins et al. (2005), no sistema produtivo atual, além da qualidade dos alimentos, o custo do processo de secagem é uma das parcelas mais importantes, podendo atingir até $20 \%$ do custo total das atividades relativas ao processamento.

Para Weber (2005), é indispensável conhecer as características do secador, como sua eficiência e o consumo de energia. A umidade do alimento ao ser inserido no secador pode influenciar o custo da secagem, visto que quanto maior a umidade, maior será o tempo de secagem e esforço do secador e, portanto, maior o custo. Assim, para obter a avaliação econômica de um sistema de secagem, deve-se considerar a quantidade de água a ser retirada do produto, a tem- peratura de operação, o tempo de secagem, o desempenho do secador e o consumo específico de energia.

A viabilidade econômica do sistema de secagem é de extrema importância, pois o custo final do produto colocado no mercado depende diretamente de todos os gastos necessários para o seu processamento, da qual a secagem é uma das etapas de grande importância no ponto de vista da conservação e do custo final do produto (Deonzeles, 2007).

No que diz respeito à secagem de peixes, existem poucos trabalhos que tratam dos custos, apesar do elevado consumo de energia e da importância que a secagem representa após a captura. As estimativas de custos servem para facilitar estudos, selecionar investimentos alternativos e determinar recursos exigidos pela atividade que se deseja implementar (Silva et al., 1992).

Assim, este artigo tem por objetivo apresentar os custos da secagem do bacalhau, mostrando o consumo energético da instalação experimental convectiva, bem como a otimização das condições de secagem para a redução deste consumo. 


\section{Materiais e Métodos}

\subsection{Consumo energético na instalação de secagem}

Na secagem de bacalhau deste estudo, os custos estão associados ao consumo energético dos diferentes atuadores da instalação experimental, nomeadamente o desumidificador, o umidificador, as resistências de aquecimento e o ventilador, conforme a tabela 1.

Tabela 1: Componentes utilizados durante a secagem

\begin{tabular}{llc}
\hline \multicolumn{1}{c}{ Componen } & \multicolumn{1}{c}{ Função } & $\begin{array}{c}\text { Potência } \\
\text { Instantânea }\end{array}$ \\
te & Aquecimento do ar & $2 \mathrm{~kW}$ \\
Resistências & & \\
Rétricas de 2kW & Aquecimento do ar & $1 \mathrm{~kW}$ \\
elétricas de 1kW & & \\
Eletro-válvula & Umidificação do ar & $0,0015 \mathrm{~kW}$ \\
Caldeira & Umidificação do ar & $2 \mathrm{~kW}$ \\
Compressor & Desumidificação do ar & $0,75 \mathrm{~kW}$ \\
Ventilador & Velocidade do ar & $0,12 \mathrm{~kW}$ \\
\hline
\end{tabular}

Para determinar o consumo em cada ensaio, foram adquiridos os sinais de saída de cada um dos controladores e, a partir destes sinais, calculadas as potências para cada um dos atuadores bem como o somatório de todos, para ter o custo final.

\subsection{Determinação dos custos energéticos}

Os custos energéticos, em cada ensaio experimental, foram calculados a partir do somatório dos custos individuais de cada um dos atuadores. Foram determinadas as funções custos para cada conjunto de umidades relativas e de temperaturas. Para fins de comparação entre ensaios, o consumo energético foi apresentado em $\mathrm{kWh}$ por hora de secagem.

\subsection{Otimização das condições de secagem para redução dos custos energéticos}

Para realizar a otimização das condições de secagem, visando a redução do consumo energético, foi feita inicialmente uma rede neural artificial para simulação do custo associado. Para esta modelagem, foi utilizada uma rede neural formada por uma camada de entrada, constituída por 4 neurônios, uma camada oculta e uma camada de saída, formada por 1 neurônio (figura 1). As entradas foram o tempo, umidade relativa, velocidade e temperatura e a saída foi o custo energético. Foi utilizada uma rede neural feedforward com o algoritmo de aprendizagem de Levenberg Marquardt e as funções de transferência tangente sigmoidal e linear para as camadas oculta e de saída, respectivamente. A camada oculta foi composta por nove neurônios. Com o modelo gerado pela RNA, foi utilizado num algoritmo de otimização baseado no método simplex proposto por Lagarias et al. (1998) a fim de obter os parâmetros de secagem ótimos para a redução do consumo energético.

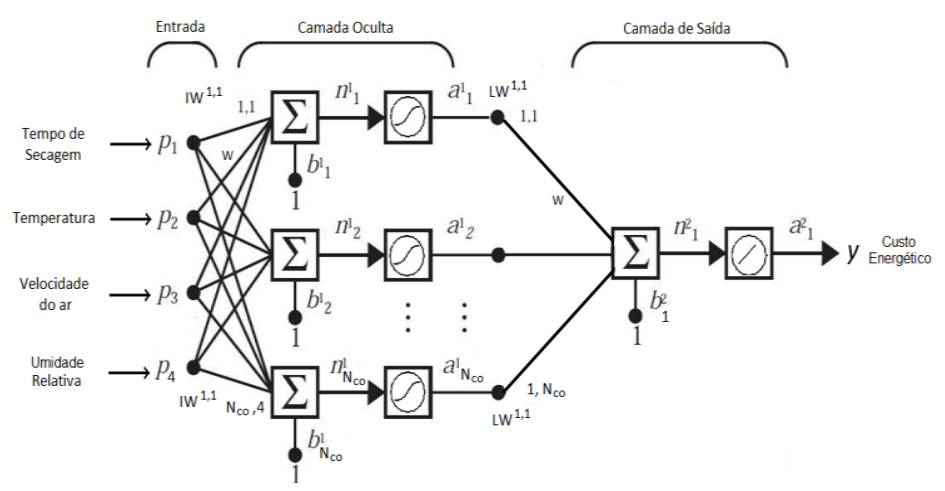

Figura 1: Estrutura da Rede Neural Artificial

\subsection{Comparação de custos para diferentes formas de umidificação}

No início da fase experimental dos ensaios de secagem de bacalhau, a umidificação era efetuada através de uma caldeira. Posteriormente, realizou-se a umidificação com recurso a uma eletroválvula, o que garantiu, além de uma maior estabilidade e rapidez na obtenção da umidade relativa desejada, uma considerável redução no consumo energético. Foi analisado e comparado o consumo energético para os diferentes ensaios realizados com umidificação através da caldeira e os realizados com a eletroválvula.

\section{Resultados e Discussões}

\subsection{Custos de secagem para diferentes condições operacionais}

Os custos de secagem obtidos para as diferentes condições operacionais são mostrados na figura 2 e tabela 2:

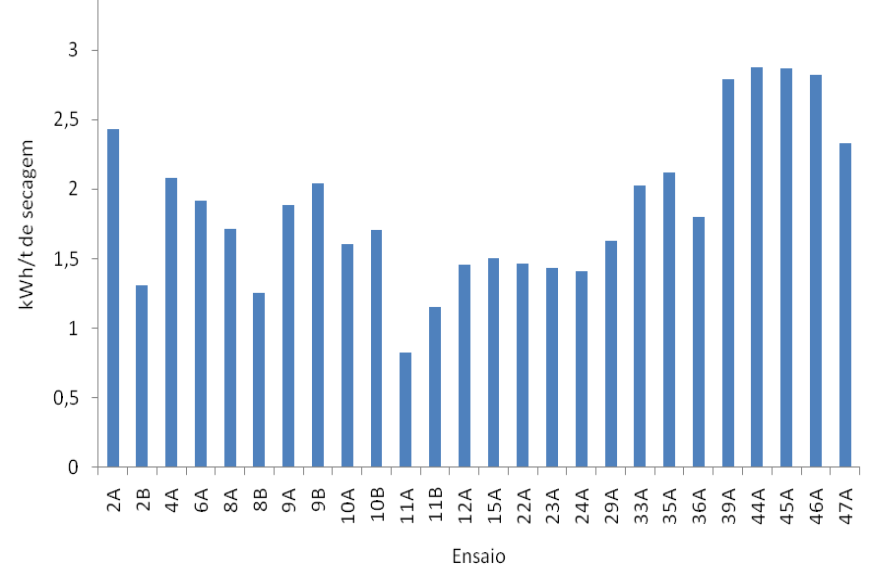

Figura 2: Consumo energético para cada ensaio em $\mathrm{kWh} / \mathrm{t}$ de secagem 
Tabela 2: Potência média para diferentes ensaios experimentais
3.3 Análise comparativa dos custos com diferentes tipos de umidificação

\begin{tabular}{|c|c|c|c|c|}
\hline Ensaio & $\mathrm{T}\left({ }^{\circ} \mathrm{C}\right)$ & UR (\%) & $\mathrm{v}(\mathrm{m} / \mathrm{s})$ & $\begin{array}{c}\text { Consumo } \\
\text { energético }(\mathrm{kWh} / \mathrm{h})\end{array}$ \\
\hline 2 & 20 & 45 & 2 & 2,43 \\
\hline 4 & 20 & 55 & 2 & 2,08 \\
\hline 6 & 20 & 65 & 2 & 1,92 \\
\hline 8 & 20 & 45 & 1,5 & 1,49 \\
\hline 9 & 20 & 50 & 1,5 & 1,96 \\
\hline 10 & 20 & 55 & 1,5 & 1,65 \\
\hline 11 & 20 & 60 & 1,5 & 1,15 \\
\hline 12 & 20 & 65 & 1,5 & 1,45 \\
\hline 15 & 15 & 50 & 2 & 1,51 \\
\hline 22 & 15 & 55 & 1,5 & 1,46 \\
\hline 23 & 15 & 60 & 1,5 & 1,44 \\
\hline 24 & 15 & 65 & 1,5 & 1,41 \\
\hline 29 & 18 & 60 & 2 & 1,63 \\
\hline 33 & 18 & 50 & 1,5 & 2,03 \\
\hline 35 & 18 & 60 & 1,5 & 2,12 \\
\hline 36 & 18 & 65 & 1,5 & 1,80 \\
\hline 39 & 23 & 50 & 2 & 2,79 \\
\hline 44 & 23 & 45 & 1,5 & 2,87 \\
\hline 45 & 23 & 50 & 1,5 & 2,87 \\
\hline 46 & 23 & 55 & 1,5 & 2,82 \\
\hline 47 & 23 & 60 & 1,5 & 2,33 \\
\hline
\end{tabular}

3.2 Resultados da otimização para os custos de secagem

Os resultados obtidos na otimização para redução do consumo energético são mostrados pela tabela 3:

Tabela 3: Condições de secagem convectiva para diferentes custos energéticos

$\begin{array}{rccll}\text { Custo } & \text { Tempo } & \text { Temperatura } & \text { Umidade } & \text { Velocidade } \\ \text { energético } & \text { (h) } & \left({ }^{\circ} \mathrm{C}\right) & \text { Relativa }(\%) & (\mathrm{m} / \mathrm{s}) \\ (\mathrm{kWh} / \mathrm{h}) & & & & \end{array}$

$\begin{array}{lllll}1,10 & 71,3 & 15 & 53,79 & 1,5 \\ 1,15 & 71,0 & 15 & 53,67 & 1,5 \\ 1,20 & 71,6 & 15 & 53,61 & 1,5\end{array}$

Observa-se que, para diferentes custos energéticos desejados, as condições ótimas permanecem constantes.

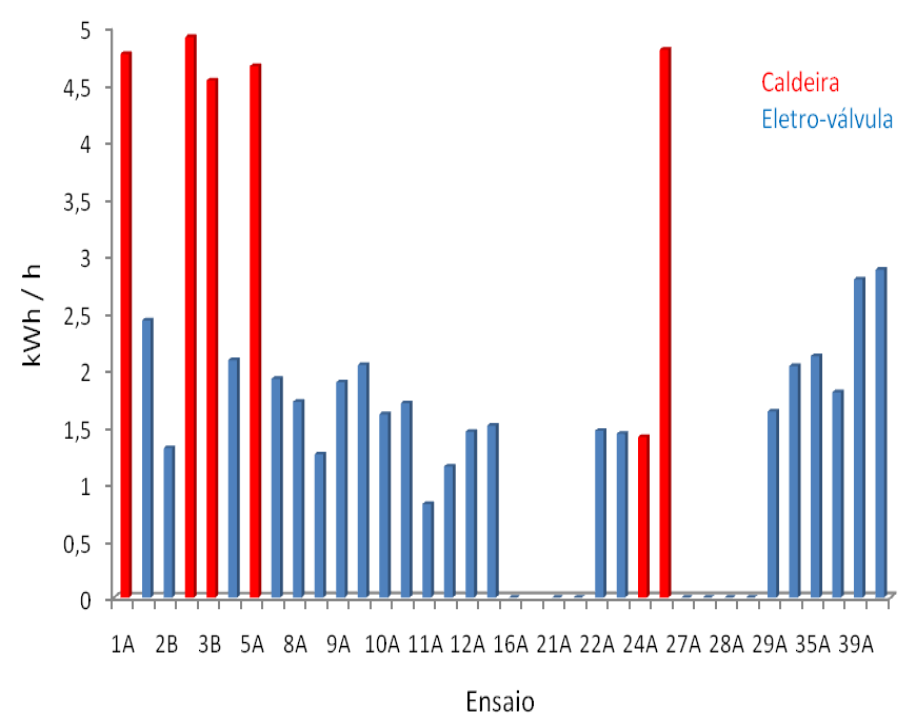

Figura 3: Comparação entre custos com umidificação $\mathrm{em} \mathrm{kWh} / \mathrm{h}$ de secagem

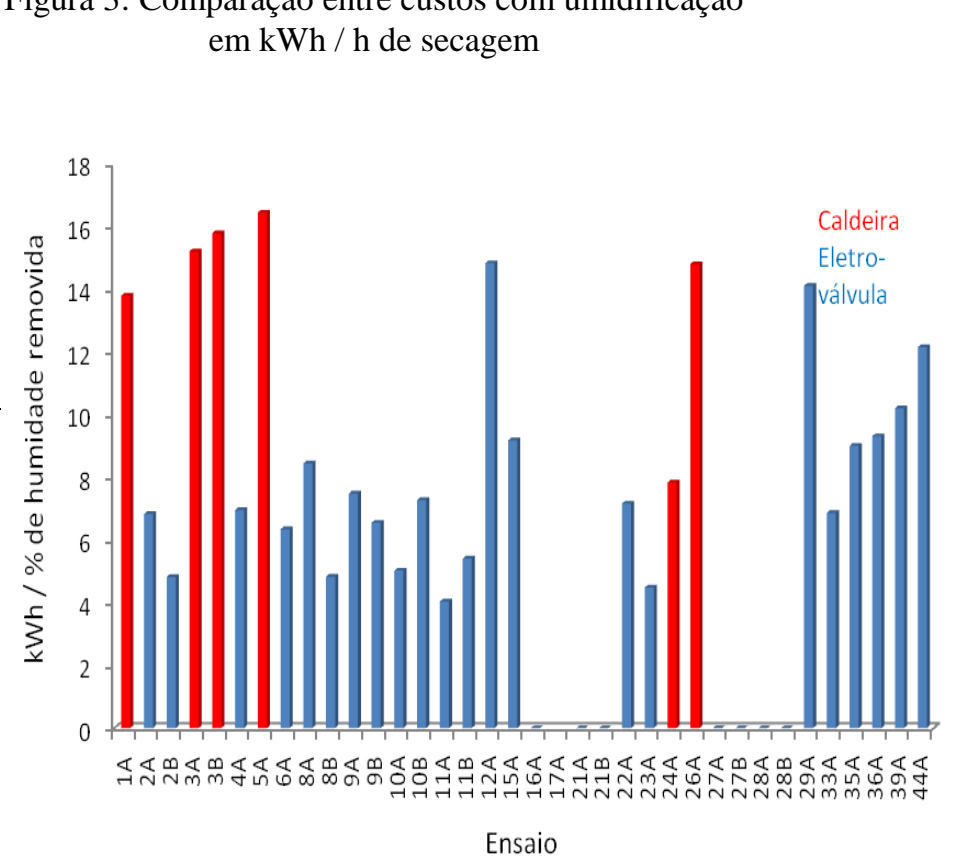

Figura 4: Comparação entre custos com umidificação

em $\mathrm{kWh} / \%$ de umidade removida

o consumo energético com a umidificação através da caldeira e com a eletroválvula.

\section{Conclusão}

Foram determinados os custos de secagem para as diferentes condições operacionais. Os custos estão associados ao consumo energético dos diferentes atuadores da instalação experimental, nomeadamente o desumidificador, o umidificador, as resistências de aquecimento e o ventilador. Os custos por hora de 
secagem variaram entre $1,15 \mathrm{kWh}$ e $2,87 \mathrm{kWh}$, com uma média de $1,94 \mathrm{kWh}$.

Foi também realizada a otimização para minimização dos custos energéticos por hora de secagem, utilizando o modelo obtido pelo treino da rede neuronal artificial. Para reduzir o consumo energético na instalação, os parâmetros de secagem devem ser: tempo de $71 \mathrm{~h}$, temperatura de $15^{\circ} \mathrm{C}$, umidade relativa de $54 \%$ e velocidade de $1,5 \mathrm{~m} / \mathrm{s}$.

\section{Agradecimentos}

Os autores agradecem à Fundação para a Ciência e a Tecnologia - FCT, pelo apoio na condução deste trabalho.

\section{Referências Bibliográficas}

S.M.L. Deonzeles, J.S. Silva, P.C. Correa, R.R. Santos, Custos comparativos da secagem de café cereja descascado em dois terreiros secadores, Engenharia na Agricultura, vol. 15, pp. 119-129, (2007).

J.C. Lagarias, J.A. Reeds, M.H. Wright, P.E. Wright, Convergence properties of the neldermead simplex method in low dimensions. SIAM J. Optim. vol. 9, pp. 112-147, (1998). DOI: $10.1137 / \mathrm{S} 1052623496303470$

C.R. Martins, J.C. Tavares, G.C. Vasconcelos, "Pós colheita de frutas de clima temperado Parâmetros de acompanhamento da maturação", UFPEL, 2005.

J.S. Silva, P.M. Sabione, A.D.L. Afonso, F. Carvalho Pinto, Avaliação de secadores e custos de secagem de produtos agrícolas, Engenharia na Agricultura, vol. 2, pp. 4-19, (1992).

E.A. Weber, "Armazenagem agrícola”, Porto Alegre, Kepler Weber Industrial, 2005.

S. Youcef-Ali, H. Messaoudi, J.Y. Desmons, A. Abene, M. Le Ray, Determination of the averagem coefficient of internal moisture transfer during the drying of a thin bed of potato slices, Journal of Food Engineering, vol. 48, pp. 95-101, (2001). DOI: $10.1016 / \mathrm{S} 0260-8774(00) 00123-0$ 